\title{
Epidemiology of myocardial infarction
}

\author{
Véronique L Roger, MD, MPH \\ Division of Cardiovascular Diseases, Department of Internal Medicine and Department of Health \\ Sciences Research, Mayo Clinic College of Medicine, Rochester Minnesota,
}

\section{Synopsis}

Myocardial infarction is a key component of the burden of cardiovascular disease. The assessment of the incidence and case fatality of myocardial infarction are important determinants of the decline in coronary disease mortality. The change in biomarker used to diagnose myocardial infarction raise a number of methodological, clinical, and public health challenges, which are discussed herein.

\section{Keywords}

myocardial infarction; incidence; community; case fatality; criteria; severity

\section{Scope of the problem}

Epidemiology can be defined as "the study of the distribution and determinants of health related events in specified populations, and the applications of this study to control health problems".

Coronary heart disease (CHD) is the number one cause of death in the Western world and as such constitutes an immense public health problem. ${ }^{2}$ While CHD mortality declined in the last four decades in the USA as life expectancy increased (http://www.cdc.gov/nchs), the use of age-adjusted rates to describe the CHD mortality obscures the fact that the decline largely represents the postponement of CHD deaths until older age. Thus, the burden of CHD is increasing in parallel with the increase in life expectancy. 3,4 As more persons live with heart disease, the burden of prevalent disease with its assorted comorbid complications is increasing. Thus, the matter of identifying persons with heart disease, measuring the incidence of disease and its outcome and how these may have changed over time becomes essential as multifaceted approaches to reduce the burden of disease including drug discovery, clinical trials and policies have shaped the practice of cardiology for decades and will likely continue to do so in the future. In this context, myocardial infarction occupies a central role in the assessment of the burden of heart disease.

Herein, we will address the occurrence of myocardial infarction across populations, place and time and examine how the epidemiology of myocardial infarction relates to the broader framework of cardiovascular population and clinical sciences.

Correspondence to Véronique L. Roger, M.D., MPH, Division of Cardiovascular Diseases, Mayo Clinic, 200 First Street SW, Rochester, MN 55905; phone \# (507) 284-0519; FAX \# (507) 266-0228, e-mail: roger.veronique @ mayo.edu.

Publisher's Disclaimer: This is a PDF file of an unedited manuscript that has been accepted for publication. As a service to our customers we are providing this early version of the manuscript. The manuscript will undergo copyediting, typesetting, and review of the resulting proof before it is published in its final citable form. Please note that during the production process errors may be discovered which could affect the content, and all legal disclaimers that apply to the journal pertain. 


\section{Methodology}

In contrast to the magnitude of the burden of heart disease, there is no nationally representative surveillance approach for heart disease. The Centers for Disease Control and Prevention conducts nationally representative surveys on hospital discharges, ambulatory medical care, risk factors, and population characteristics, while the Agency for Healthcare Research and Quality collects information on medical expenditures and hospital inpatient samples. Death certificate data are collected by state health departments and gathered by Centers for Disease Control and Prevention, and the Centers for Medicare and Medicaid Services collect data pertaining to Medicare hospital reimbursements. However, these systems are not designed to be linked and thus can only provide a partial assessment of the morbidity and mortality related to heart disease.

Measuring the occurrence of myocardial infarction in diverse populations and settings requires that several conditions be met. These include the availability of a defined population which is indispensable to generate incidence rates and the reliance on a valid definition that actually measures the intended event. This definition should be amenable to standardization to enable reliable data collection and comparisons across studies. Finally, the components of this definition should be relatively immune to temporal changes so that time trends in the occurrence of myocardial infarction can be appraised. Despite their apparent simplicity, these conditions are rarely met. We will review below the commonly used approaches to assess the burden of myocardial infarction along with their respective advantages and disadvantages.

The National Hospital Discharge Survey samples hospital discharges using codes from the International Classification of Disease (ICD), ${ }^{5}$. These are event-based, not person-based, and thus allow for multiple hospitalizations for the same individual to be counted. The diagnoses are not validated using standardized criteria such that myocardial infarction may reflect different entities across hospitals depending on care delivery patterns, themselves depending on insurance coverage, medical practice habits, etc. ${ }^{6}$

Further, National Hospital Discharge Survey data do not differentiate between first and subsequent admission for a given condition and thus cannot measure incidence. Finally, documented shifts in hospital discharge diagnoses after the introduction of the DiagnosisRelated Groups payment system hinders the validity of these sources for epidemiology research. ${ }^{7-9}$ Thus, while hospital discharge data provide important insights into the burden of disease which is important for resource allocation, policy making and analysis of health care delivery, it cannot provide information on the true epidemiology of myocardial infarction.

Community surveillance can be envisioned as a comprehensive multifaceted approach designed to track heart disease at the community level. It has proven feasible and less costly than a cohort study (Gillum, J Chronic Disease 1978). Typical indicators tracked in community surveillance of heart disease include deaths, myocardial infarction incidence and outcomes and less frequently heart failure incidence and outcomes. Because it is conducted within a defined population, community surveillance enables measuring attack rates for myocardial infarction and, in some cases, incidence rates. In the absence of a national surveillance system for heart disease, community surveillance is essential to precisely monitor heart disease trends. These programs share a number of common key features. They are retrospective by design and typically rely on dismissal diagnosis using codes of the International Classification of Diseases (ICD) for case finding. Once potential cases are identified, they are subjected to rigorous validation procedures using standardized diagnostic approaches, most often incorporating coding of the electrocardiographic findings with the Minnesota code, ${ }^{10}$ which can be accomplished manually or electronically. ${ }^{11}$ We will review below the main characteristics of heart disease community surveillance programs. 
The Minnesota Heart Survey (MHS) has been monitoring hospitalized MI along with CHD deaths among residents of the Minneapolis-St. Paul metropolitan area since the 1970s. It relies on a standardized definition for myocardial infarction that combines cardiac pain, biomarkers and Minnesota coding of the electrocardiogram ${ }^{12}$ and has in place rigorous quality assurance and quality control measures.

The surveillance component of the Atherosclerosis Risk in Communities (ARIC) study was originally designed to evaluate CHD incidence differences by race and by geographic location; however has adequate power to assess trends. ${ }^{13,} 14$ ARIC relies on a standardized definition for myocardial infarction that combines cardiac pain, biomarkers and Minnesota coding of the electrocardiogram. Like the Minnesota Heart Survey, ARIC has in place rigorous quality assurance methodology (White). Initially, ARIC had an upper age limit of 74 years, which has since been extended to include a growing segment of the aging US population.

The Olmsted County Study is conducted under the auspices of the Rochester Epidemiology Project, which has a long standing tradition of monitoring disease occurrence and outcomes of many chronic diseases. ${ }^{15-17}$ Heart disease surveillance within the population of Olmsted County examined myocardial infarctions and cardiac deaths since 1979. The study uses standardized epidemiological diagnostic criteria for myocardial infarction similar to those of the ARIC study, including Minnesota coding of the electrocardiogram, and has in place rigorous quality control measures. ${ }^{18}$ The Olmsted County Study has no upper age limit and has access to out patient as well as inpatient data, which is essential to evaluate long term outcomes after myocardial infarction given the current shift from in-patient care settings.

The Worcester Heart Attack Study is a multi-hospital community study that focuses on trends in the incidence and mortality of hospitalized MIs in all age groups. ${ }^{19,}{ }^{20}$ It relies on a standardized definition of myocardial infarction combining chest pain, biomarkers and electrocardiogram data without Minnesota coding of the electrocardiogram.

The Framingham Heart Study is a prospective study of cardiovascular disease and its determinants among a sample of residents of the town of Framingham, Massachusetts. As a population based cohort focusing on risk factors for the development of heart disease, it has generated transformational discoveries which shaped the practice of cardiology for more than half a century. Longitudinal trends in disease occurrence and outcomes including myocardial infarction have also been evaluated in the Framingham Heart Study under the auspices of the Framingham Cardiovascular Disease Survey. ${ }^{21,22}$ The Framingham Cardiovascular Disease Survey defined myocardial infarctionas a combination of symptoms, electrocardiographic and enzymes changes.

The Corpus Christi Heart Project was designed to focus on the comparison of disease burden and outcome between Mexican Americans and Whites. ${ }^{23,} 24$ To define myocardial infarction, the Corpus Christi Heart Project relied on a standardized definition of myocardial infarction combining cardiac pain, biomarkers and electrocardiogram data with Minnesota coding of the electrocardiogram.

The World Health Organization (WHO) MONICA (Multinational MONItoring of trends and determinants in CArdiovascular disease) Project was established in the early 1980s to monitor trends in cardiovascular diseases and to relate these to risk factor changes. ${ }^{25}$ It was set up to explain the diverse trends in cardiovascular disease mortality observed from the 1970s. There were a total of 32 MONICA centers in 21 countries. The population monitored included ten million men and women, age 25-64 years. The diagnosis of myocardial infarction integrates cardiac pain, Minnesota code of the electrocardiograms and biomarker levels (http://www4.ktl.fi/publications/monica/manual). ${ }^{26,27}$ The breadth of populations covered by MONICA is unique and the data exceptionally rich. However, to interpret MONICA data, 
it is essential to remember that the upper age limit of 64 years does not account for a large segment of the population in which coronary events and myocardial infarctions occur.

FINAMI is a population-based MI registry initiated as part of the FINMONICA study and was originally the Finnish contribution to the MONICA Project. ${ }^{28}$ FINAMI evaluates all events compatible with myocardial infarction or coronary heart disease death among residents of several geographical areas in Finland. These areas are mostly urban, and in 1995, there were 82849 men and 87360 women age 35-64 years living in the FINAMI areas. The FINAMI registry ensures complete capture and ascertainment of all coronary events and relies on a standardized definition of myocardial infarction combining cardiac pain, biomarkers and electrocardiogram data with Minnesota coding of the electrocardiogram. 29

Finally, myocardial infarction registries are currently active, including, in particular, the National Registry of Myocardial Infarction (NRMI) and the Global Registry of Acute Coronary Events (GRACE). Sponsored by Genentech, Inc. NRMI is a large observational study of acute myocardial infarction (http://www.nrmi.org/nrmi; web site last accessed 09-01-2006). Since 1990, NRMI has collected data on more than 2 million patients in the United States with a central focus on care delivery and short term outcomes. NRMI is a voluntary, industrysponsored registry that cannot measure incidence rates in populations. GRACE is a multinational observational study of management and outcomes of acute coronary syndromes. 30 It uses a cluster design involving sites in the USA, Brazil, Europe, Argentina and Australia. The diversity of the populations and attending patterns of practice is a unique feature of GRACE, yet like NRMI its main focus is on the delivery of care. As such, these important registries and other smaller similar studies provide essential data for outcomes research, particularly as it relates to health care delivery. However, it cannot by design provide information on incidence rates and cannot measure the true population burden of myocardial infarction and how it may have changed over time.

In summary, several well-established studies conduct surveillance of heart disease using the appropriate methodology within defined populations to provide data on the epidemiology of myocardial infarction. These studies have included myocardial infarction as one of their central measures and use well-validated criteria anchored within solid quality assurance that rely on 3 central elements cardiac pain, electrocardiographic analysis and biomarker changes. Each of the aforementioned surveillance programs has a slightly different appraisal of this important public health problem and thus provides complementary information. It is important to emphasize that, while some studies such as ARIC and Corpus Christ Heart Study have been designed to enable analysis of diverse ethnic groups, others have more limited ethnic diversity. As no study by itself could ever be representative of all ethnic groups, this further supports the need for a national surveillance approach for myocardial infarction and coronary disease, which is currently lacking. The lack of a national surveillance approach hinders the understanding of heart disease and reduces the ability to accurately treat it and prevent it.

\section{Incidence of myocardial infarction}

Selected results pertaining to the incidence of myocardial infarction and how it changed over time are presented in Table 1. These results call for several comments.

In the ARIC ${ }^{31}$ study, no overall change was detected in the incidence of hospitalized myocardial infarction between 1987 and 1994. There were divergences in the trends by race and sex with an alarming increase in myocardial infarction among black women. In the Minnesota Heart Survey, between 1985 and 1995, the rates of hospitalization for acute myocardial infarction declined. ${ }^{32,} 33$ In both MHS and ARIC, published data do not include persons older than age 74 and is thus not accounting for a growing segment of the population. 
In the Worcester Heart Attack Study, analyses spanning a 20-year period until 1995 indicated qualitatively flat trends in incidence from the mid 1980s to the mid 1990s. ${ }^{34}$ The trends between 1975-88 underscored the importance of examining age and sex-specific patterns in addition to overall rates. Indeed, larger declines in myocardial infarction incidence were noted among elderly individuals along with an increase in incidence among some but not all age groups in women.

In Olmsted County, there was little change in the incidence of hospitalized myocardial infarction between 1979 and 1998. However, important age and sex-specific patterns were noted as trends diverged with an increase in myocardial infarction incidence in women and the elderly. ${ }^{35,36}$ It is important to underscore that in the Olmsted County Study, like in the Worcester Heart Attack Study, the absence of an upper age limit enables the detection of age and sex-specific disease patterns that denote a shift in the burden of myocardial infarction towards women and the elderly. These findings have important clinical and public health implications.

Data from the Framingham Heart Study, which pertain to earlier time periods since the inception of the cohort, indicated that the incidence of myocardial infarction and other manifestations of coronary disease declined over a twenty year period starting in the 1950's. 37

The Corpus Christi Study reported important data comparing and contrasting the incidence of myocardial infarction in Mexican American and non-Hispanic White men and women indicating that the incidence of myocardial infarction was greater among Mexican Americans than non-Hispanic Whites for both men and women. ${ }^{24}$ The diversity of the populations included in MONICA precludes summarizing its rich data in one aggregate measure amenable to inclusion in Table 1. MONICA reported seminal data illustrating a wide variation in the incidence of myocardial infarction and other coronary events across populations. ${ }^{26,27}$

\section{Case fatality rate after myocardial infarction}

Selected results pertaining to the case fatality rate after myocardial infarction and how it changed over time are presented in Table 2. Several points should be underscored to enable appropriate interpretation of these results. Firstly, the ARIC and MHS studies do not reflect the disproportionate burden of death after myocardial infarction that occurs in the elderly because their published results do not include persons above age 74. Secondly, the Worcester Heart Attack Study has reported on in-hospital mortality, which is problematic over the 20year time span of their study given the marked reduction on the duration in hospital stay that occurred during that time period. Thus, 28-day case fatality is a better metric to appraise the change in mortality after acute MI within the context of changing practice in hospitalization duration. These important considerations notwithstanding, all studies have reported a favorable decline in early mortality after acute myocardial infarction among younger individuals with a persistently high case fatality rate among the elderly. The mortality of acute myocardial infarction in community surveillance studies remains high and is consistently higher than that reported in clinical trials, reflective of the bias ensuing from the rigorous selection process necessary for the internal validity of clinical trials. ${ }^{38}$ While clinical trials are the only valid approach to test the efficacy of a novel treatment, the data from community surveillance reflect the effectiveness of these new treatments once implemented in clinical practice, thereby underscoring how complementary the two approaches are.

\section{Severity of myocardial infarction}

Epidemiological studies offer the possibility of examining whether the severity of acute myocardial infarction differs according to time, place and persons. Some of the aforementioned 
surveillance programs have primarily evaluated if the severity of myocardial infarction declined over time.

While epidemiology studies constitute the only environment where this question can be addressed given the need for a reference population as well as for rigorous definition and criteria, evaluating the severity of myocardial infarction is challenging for multiple reasons. ${ }^{39}$

Firstly, the time between the onset of symptoms and the presentation to medical care can affect each indicator of severity (Killip class, biomarkers, electrocardiographic findings), such that time trends in time to presentation can affect any association between time and infarction severity. Secondly, some indicators can be affected by treatment. While Killip class and STsegment elevation reflect the characteristics of the infarction during the first twenty-four hours and are unlikely to be affected by treatment, peak CK and Q-waves conversely may be impacted by treatment, particularly reperfusion. Thirdly, the interpretation of the changes in Killip class requires knowledge in the trends in out-of-hospital coronary disease deaths, since a decline in such deaths may result in larger numbers of persons admitted to the hospital who would have died out of hospital. This, in turn, may impact the relationship between Killip class and time by modifying the case mix of hospitalized infarctions. Finally, accurate determination of the severity of infarction through biomarker measurement will be affected by the timing and frequency of the biomarker measurements such that the recorded values may not accurately reflect the true peak.

Overall, among studies that included all age groups, the frequency of cardiogenic shock declined some over time although the magnitude of the decline was attenuated after age adjustment. ${ }^{40-42}$

The frequency of ST-segment elevation at presentation and the occurrence of Q waves decreased over time in the Olmsted County Study 40,41 while in the ARIC study, the frequency of these indicators increased (ST segment elevation) or remained stable (Q-waves). ${ }^{43} \mathrm{It}$ is conceivable that differences in age distributions between studies contribute to this discrepancy. Notwithstanding these possible explanations, these findings underscore the importance of continuous monitoring of such trends across time and age groups.

Peak CK values declined in the ARIC and in the Olmsted County studies 43,44 These are influenced by reperfusion therapy, the use of which increased during the surveillance period for both studies. However, the decline in peak CK was observed among all patients in Olmsted County irrespective of reperfusion therapy, such that it can be viewed as a pertinent indicator of MI severity 44

Altogether, within the methodological caveats mentioned above, the data from published studies converge to suggest a decline in the severity of myocardial infarction over time.

\section{The new definition of myocardial infarction}

In 2000, the American College of Cardiology and the European Society of Cardiology published a consensus document redefining myocardial infarction. ${ }^{45}$ The new definition combined rise and fall of biochemical markers of myocardial necrosis with any of the following conditions: ischemic symptoms, ECG changes, and coronary intervention. The recommended biochemical markers are the troponins (T or I), which have gradually replaced CK and CKMB in clinical practice since the mid 1990s. These changes stem largely from reports on the prognostic value of troponin indicating that troponin provided prognostic information incremental to previously available clinical factors. ${ }^{46-48}$ 
Troponin is more specific than CK/CK-MB for the diagnosis of myocardial infarction in the setting of associated skeletal muscle damage or injury including surgery. Of critical importance to clinicians and epidemiologists, the troponins have higher sensitivity which allows for the detection of very small amounts of myocardial necrosis, which would have gone undetected by CK-MB. Proponents of the new definition recognized that the change in myocardial infarction criteria, particularly as they rely highly on more sensitive biochemical markers, "will confuse efforts to follow trends in disease rates and outcomes." 45 The implications of changing the criteria for the diagnosis of MI, however, reach far beyond their impact on the study of the epidemiology of myocardial infarction and the discontinuity in the trends that this change will unavoidably introduce. Indeed, the new definition can be expected to increase the number of myocardial infarctions and shift the clinical spectrum of the disease. For example, patients previously diagnosed with unstable angina will now be classified as myocardial infarction because of detectable troponin levels despite normal CK-MB. Altogether, the new criteria generated considerable controversy on their appropriateness and their degree of reliance on troponin. ${ }^{49-54}$

The controversy notwithstanding, because of the profound consequences of a diagnosis of myocardial infarction on patient care, disease trends and utilization of health care resources, it is of critical importance for clinicians and public health to critically evaluate the impact of the new criteria on incidence, case mix and outcome. Anticipating these concerns, the proponents of the new definition had recommended that the established definition of MI be "retained by specific epidemiological centers". This recommendation is challenging, however, for most surveillance programs which rely on multiple hospitals and health care systems for case finding. Indeed, unless CK-MB and cardiac troponins are measured simultaneously in the same patients in a population-based setting, the shifts in incidence, case mix and outcomes resulting from the change in criteria cannot be accurately measured. The simultaneous measurements of the two biomarkers and the determination of the impact of the changes in myocardial infarction diagnosis require active surveillance with an approach that apply simultaneously the creatine kinase and troponin-based criteria to all patients with acute coronary syndrome in a given population, irrespective of the clinical practice patterns. The enunciation of these prerequisites underscores the complexity of designing such as study.

Studies that examined the impact of troponin on the diagnosis of myocardial infarction used mostly convenience samples from case series and often single values of troponin. $15,55-58$ All documented increases in the number of myocardial infarctions, but the estimates of the magnitude of the increase varied widely from $23 \% 15,59$ to $195 \% .57$ The interpretation of these data is quite complex as the type of biomarker (troponin T versus I), the assays and cutpoints differed across studies as did the reference criteria used. These important methodological limitations $11,60-62$ hinder the inference from these data. Finally, all studies used single values of troponin and thus did not evaluate the increment in the number of infarctions related to rise and fall in troponin values, the recommended approach in the new definition. 63

In the FINAMI study, ${ }^{64}$ the impact of troponin was addressed by examining the trends in coronary disease events in Finland over a decade (1993 to 2002). Among persons age 35 to 74 years, the incidence of the first coronary event declined by $2 \%$ per year in men and $1 \%$ per year in women. The decline was statistically significant in men but not in women. Among persons age 75 or greater, the incidence of first coronary events did not change. The authors applied coefficients derived from a large number of infarctions with simultaneous determination of troponin and enzymatic markers to correct for the use of troponin. Correcting for the effect of troponin resulted in unmasking a larger decline in the incidence of first coronary events in both sexes and all age groups. These key findings thus directly validate the concern stemming from the redefinition of myocardial infarction by documenting that the change in 
the biomarker indeed "confuses" the interpretation of temporal trends in coronary disease (Alpert).

In the Olmsted County Study, active (otherwise termed prospective) surveillance was implemented to examine the impact of the redefinition of myocardial infarction in the community ${ }^{65}$ The data demonstrates that the prospective and rigorous application of the new criteria relying on dynamic changes in troponin values results in a $68 \%$ increase in the number of infarctions compared to the number of infarctions that would have been detected using previous used criteria relying on the biomarkers creatine kinase and its MB fraction. The use of single troponin values provides different results than the criteria relying on rise and fall. The increments in the number of infarctions, importantly, are always large even with conservative cut-points and likely to increase as limits of normal of the troponin assays are lowered. Further, this study also underscored the frequency of potentially spurious elevation of troponin 58 ,

66 in clinical practice. ${ }^{65}$

\section{Interpretation of the changes in the epidemiology of myocardial infarction}

Studying the trends in the incidence and outcome of myocardial infarction and of coronary disease mortality provides crucial insights into the determinants of heart disease which is essential to its treatment and prevention. For example, a decline in coronary mortality with stable incidence trends most likely reflects the impact of secondary prevention and medical care, whereas declining incidence of disease would point to primary prevention as the main driver of mortality trends. Within this framework, it is important to recognize that the trends in the incidence and outcome of coronary disease are complex, likely multifactorial and evolve over time.

Altogether, from the early to mid 1980s until the mid to late 1990s within the context of a decline in coronary disease mortality, the incidence of myocardial infarction declined little (even increased in certain groups) while case fatality improved. This suggests that medical care played a major role in the genesis of the decline of coronary deaths. This observation resonates with the dramatic changes in the treatment of acute coronary disease that has marked this time period and suggests that the changes in treatment approaches have been translated to the community resulting in important survival benefits. During this time period, by contrast, the impact of primary prevention as measured by the incidence of myocardial infarction appears more modest, contrasting with its impact in earlier years marked by a reduction in the incidence of myocardial infarction. ${ }^{37}$ This demonstrates that the determinants of coronary mortality are multifactorial and that the respective responsibilities of changing incidence and reduced fatalities change over time. Thus, as the respective role of these two theoretical determinants varies across person, time and place, continued surveillance is essential to detect changes in the trends and their determinants and to evaluate the effectiveness of clinical and public health strategies to combat coronary disease. $31,67,68$

\section{Epidemiology and clinical practice}

As discussed above, traditional studies of the epidemiology of myocardial infarction have focused on infarction and have seldom reported on the clinical entity of acute coronary syndromes, with or without biomarker elevation. Part of the reason for this resides in the need for a standardized definition in epidemiology and the relative ease of standardizing the definition of myocardial infarction, contrasting with the more challenging task of defining acute coronary syndromes from an epidemiological point of view particularly in forms without biomarker elevation and with transient or absent electrocardiographic changes. Thus, over the years, epidemiological studies did not account for a large segment of the burden of non-fatal coronary disease, namely acute coronary syndromes, that do not meet validated infarction 
criteria. The redefinition of myocardial infarction has underscored this important issue, thereby challenging epidemiologists to incorporate acute coronary syndromes in the surveillance of coronary disease. Indeed, studies that have evaluated the implications of the redefinition of myocardial infarctions illustrate that reliance on one biomarker or the other will alter the categorization between types of acute coronary syndromes. ${ }^{64,65}$ Advocates of the widespread use of troponin have argued that acute coronary syndromes represent a continuum of disease, a concept quite familiar to clinicians, and that any increase in cardiac biomarkers have prognostic implications. However, while the implications of the shift across types of acute coronary syndromes may arguably be rather modest from a clinical and pathophysiological point of view, the consequences of a diagnosis of myocardial infarction for employment, health insurance, evaluation of health care delivery, epidemiology and public health are enormous.

For this reason, operational definitions of acute coronary syndromes have been proposed that include a purposeful effort to categorize such events while also specifically identifying myocardial infarctions that would have met criteria using the previous enzymatic biomarkers. 69 This approach would enable health care providers to relate the newly defined myocardial infarctions to the previous classification. ${ }^{69}$ Thus, as the new myocardial infarction criteria generate continued reflection and discussion, more data on their clinical and epidemiological implications are clearly needed. This underscores the need to broaden the approach to coronary disease surveillance to include acute coronary syndromes rather than focusing primarily on myocardial infarction as traditionally defined. This is critical to understanding the trends that will be measured over the next decade marked by the change in biomarkers and to accurately evaluate the burden of heart disease.

\section{Acknowledgements}

Supported in part by grants from the National Institutes of Health (RO1 HL 59205, K24 HL 68765).

\section{References}

1. Last, JM. Dictionary of epidemiology. Vol Oxford University Press; New York, NY: 2000.

2. Thom, T.; Haase, N., et al. Writing Group Members. Heart Disease and Stroke Statistics--2006 Update. Circulation; A Report From the American Heart Association Statistics Committee and Stroke Statistics Subcommittee; January 11, 2006; 2006. CIRCULATIONAHA.105.171600

3. Bishop E. Heart disease may actually be rising; researchers claim deaths are now being delayed to a later age group. Wall Street Journal. November 13, 1996;1996 pB3(W) pB6(E) col 1 (11 col in)

4. Gerber Y, Jacobsen SJ, Killian J, Weston S, Roger VL. Impact of Participation Bias in a PopulationBased Study of Myocardial Infarction in Olmsted County, Minnesota, 2002 to 2004. Circulation 2006;13:e827.

5. Gillum RF. Acute myocardial infarction in the United States, 1970-1983. American Heart Journal 1987;113(3):804-811. [PubMed: 3825869]

6. Feinleib, M.; Lentzner, H.; Collins, J.; Pokras, R.; Havlik, R. Regional variations in coronary heart disease mortality and morbidity. In: Luepker, Ha, editor. Trends in coronary heart disease mortality. Oxford University Press; 1988.

7. Assaf AR, Lapane KL, McKenney JL, Carleton RA. Possible influence of the prospective payment system on the assignment of discharge diagnoses for coronary heart disease. New England Journal of Medicine 1993;329(13):931-935. [PubMed: 8361508]

8. Jollis JG, Ancukiewicz M, DeLong ER, Pryor DB, Muhlbaier LH, Mark DB. Discordance of databases designed for claims payment versus clinical information systems. Implications for outcomes research. Annals of Internal Medicine 1993;119(8):844-850. [PubMed: 8018127]

9. Psaty BM, Boineau R, Kuller LH, Luepker RV. The potential costs of upcoding for heart failure in the United States. Am J Cardiol 1999;84(1):108-109. A109. [PubMed: 10404865]

10. Prineas, R.; Crow, R.; Blackburn, H. The Minnesota Code Manual of Electrocardiographic Findings. Littleton, Massachusetts: John Wright-PSG, Inc; 1982. 
11. Kors JA, Crow RS, Hannan PJ, Rautaharju PM, Folsom AR. Comparison of computer-assigned Minnesota Codes with the visual standard method for new coronary heart disease events. Am J Epidemiol Apr 15;2000 151(8):790-797. [PubMed: 10965976]

12. Gillum RF, Fortmann SP, Prineas RJ, Kottke TE. International diagnostic criteria for acute myocardial infarction and acute stroke. American Heart Journal 1984;108(1):150-158. [PubMed: 6731265]

13. White AD, Folsom AR, Chambless LE, et al. Community surveillance of coronary heart disease in the Atherosclerosis Risk in Communities (ARIC) Study: methods and initial two years' experience. J Clin Epidemiol 1996;49(2):223-233. [PubMed: 8606324]

14. The ARIC Investigators. The Atherosclerosis Risk in Communities (ARIC) Study: design and objectives. American Journal of Epidemiology 1989;129:687-702. [PubMed: 2646917]

15. Melton LJ 3rd. History of the Rochester Epidemiology Project. Mayo Clinic Proceedings 1996;71 (3):266-274. [PubMed: 8594285]

16. Melton LJ 3d. Selection bias in the referral of patients and the natural history of surgical conditions. Mayo Clinic Proceedings 1985;60(12):880-885. [PubMed: 4068763]

17. Kurland, LT.; Elveback, LR.; Nobrega, FT. Population studies in Rochester and Olmsted County, Minnesota, 1900-1968. In: Kessler, IT.; Levin, ML., editors. The Community as an Epidemiologic Laboratory; a casebook of community studies. Baltimore, MD: Johns Hopkins Press; 1970. p. 47-70.

18. Roger VL, Killian J, Henkel M, et al. Coronary disease surveillance in Olmsted County objectives and methodology. J Clin Epidemiol 2002;55(6):593-601. [PubMed: 12063101]

19. Goldberg RJ, Gore JM, Alpert JS, Dalen JE. Recent changes in attack and survival rates of acute myocardial infarction (1975 through 1981). The Worcester Heart Attack Study. Jama 1986;255(20): 2774-2779. [PubMed: 3701991]

20. Goldberg RJ, Gorak EJ, Yarzebski J, et al. A communitywide perspective of sex differences and temporal trends in the incidence and survival rates after acute myocardial infarction and out-ofhospital deaths caused by coronary heart disease. Circulation 1993;87(6):1947-1953. [PubMed: 8504508]

21. Gillum RF, Feinleib M, Margolis JR, Fabsitz RR, Brasch RC. Community surveillance for cardiovascular disease: the Framingham cardiovascular disease survey. Some methodological problems in the community study of cardiovascular disease. Journal of Chronic Diseases 1976;29 (5):289-299. [PubMed: 939793]

22. Margolis JR, Gillum RF, Feinleib M, Brasch R, Fabsitz R. Community surveillance for coronary heart disease: the Framingham Cardiovascular Disease survey. Comparisons with the Framingham Heart Study and previous short-term studies. Am J Cardiol Jan;1976 37(1):61-67. [PubMed: 942677]

23. Nichaman MZ, Wear ML, Goff DC Jr, Labarthe DR. Hospitalization rates for myocardial infarction among Mexican-Americans and non-Hispanic whites. The Corpus Christi Heart Project. Ann Epidemiol 1993;3(1):42-48. [PubMed: 8287155]

24. Goff DC, Nichaman MZ, Chan W, Ramsey DJ, Labarthe DR, Ortiz C. Greater incidence of hospitalized myocardial infarction among Mexican Americans than non-Hispanic whites. The Corpus Christi Heart Project, 1988-1992. Circulation 1997;95(6):1433-1440. [PubMed: 9118510]

25. The World Health Organization MONICA Project (monitoring trends and determinants in cardiovascular disease): a major international collaboration. WHO MONICA Project Principal Investigators. J Clin Epidemiol 1988;41(2):105-114. [PubMed: 3335877]

26. Tunstall-Pedoe H, Kuulasmaa K, Mahonen M, Tolonen H, Ruokokoski E, Amouyel P. Contribution of trends in survival and coronary-event rates to changes in coronary heart disease mortality: 10-year results from 37 WHO MONICA project populations. Monitoring trends and determinants in cardiovascular disease [see comments]. Lancet 1999;353(9164):1547-1557. [PubMed: 10334252]

27. Tunstall-Pedoe H, Kuulasmaa K, Amouyel P, Arveiler D, Rajakangas AM, Pajak A. Myocardial infarction and coronary deaths in the World Health Organization MONICA Project. Registration procedures, event rates, and case-fatality rates in 38 populations from 21 countries in four continents. Circulation Jul 1994;90(1):583-612.

28. Mahonen M, Salomaa V, Torppa J, et al. The validity of the routine mortality statistics on coronary heart disease in Finland: comparison with the FINMONICA MI register data for the years 19831992. Finnish multinational MONItoring of trends and determinants in CArdiovascular disease. J Clin Epidemiol Feb 1999;52(2):157-166. 
29. Salomaa V, Ketonen M, Koukkunen H, et al. Trends in coronary events in Finland during 1983-1997. The FINAMI study. Eur Heart J Feb;2003 24(4):311-319. [PubMed: 12581678]

30. Rationale and design of the GRACE (Global Registry of Acute Coronary Events) Project: a multinational registry of patients hospitalized with acute coronary syndromes. Am Heart J Feb;2001 141(2):190-199. [PubMed: 11174331]

31. Rosamond WD, Chambless LE, Folsom AR, et al. Trends in the incidence of myocardial infarction and in mortality due to coronary heart disease. New England Journal of Medicine 1998;339:861867. [PubMed: 9744969]

32. McGovern PG, Pankow JS, Shahar E, et al. Recent trends in acute coronary heart disease--mortality, morbidity, medical care, and risk factors. The Minnesota Heart Survey Investigators. New England Journal of Medicine 1996;334(14):884-890. [PubMed: 8596571]

33. McGovern PG, Jacobs DR Jr, Shahar E, et al. Trends in acute coronary heart disease mortality, morbidity, and medical care from 1985 through 1997: the Minnesota heart survey. Circulation 2001;104(1):19-24. [PubMed: 11435332]

34. Goldberg RJ, Yarzebski J, Lessard D, Gore JM. A two-decades (1975 to 1995) long experience in the incidence, in-hospital and long-term case-fatality rates of acute myocardial infarction: a community-wide perspective. J Am Coll Cardiol 1999;33(6):1533-1539. [PubMed: 10334419]

35. Roger VL, Jacobsen SJ, Weston SA, et al. Trends in the incidence and survival of patients with hospitalized myocardial infarction, Olmsted County, Minnesota, 1979 to 1994. Ann Intern Med Mar 5;2002 136(5):341-348. [PubMed: 11874305]

36. Arciero TJ, Jacobsen SJ, Reeder GS, et al. Temporal trends in the incidence of coronary disease. Am J Med Aug 15;2004 117(4):228-233. [PubMed: 15308431]

37. Sytkowski PA, D’Agostino RB, Belanger A, Kannel WB. Sex and time trends in cardiovascular disease incidence and mortality: the Framingham Heart Study, 1950-1989. Am J Epidemiol 1996;143 (4):338-350. [PubMed: 8633618]

38. Lindsted KD, Fraser Ge, Steinkohl M, Beeson WL. Healthy volunteer effect in a cohort study: Temporal resolution in the adventist health study. Journal of Clinical Epidemiology 1996;49(7):783790. [PubMed: 8691229]

39. Goldberg RJ. Monitoring trends in severity of acute myocardial infarction: challenges for the next millennium. Am Heart J 2000;139(5):767-770. [PubMed: 10783207]

40. Hellermann JP, Reeder GS, Jacobsen SJ, Weston S, Killian J, Roger VL. Longitudinal Trends in the Severity of Acute Myocardial Infarction: A Population Study in Olmsted County, MN. American Journal of Epidemiology 2002;156:246-253. [PubMed: 12142259]

41. Hellermann JP, Goraya TY, Jacobsen SJ, et al. Incidence of heart failure after myocardial infarction: Is it changing over time? Am J Epidemiol 2003;157:1101-1107. [PubMed: 12796046]

42. Goldberg RJ, Samad NA, Yarzebski J, Gurwitz J, Bigelow C, Gore JM. Temporal trends in cardiogenic shock complicating acute myocardial infarction. N Engl J Med 1999;340(15):11621168. [PubMed: 10202167]

43. Goff DC Jr, Howard G, Wang CH, et al. Trends in severity of hospitalized myocardial infarction: the atherosclerosis risk in communities (ARIC) study, 1987-1994. Am Heart J 2000;139(5):874-880. [PubMed: 10783222]

44. Hellermann JP, Reeder GS, Jacobsen SJ, Weston S, Killian J, Roger VL. Has The Severity of Acute Myocardial Infarction Changed Over Time? A Population-Based Study in Olmsted County, MN. Circulation 2001;104:II-787.

45. Myocardial infarction redefined--a consensus document of The Joint European Society of Cardiology/ American College of Cardiology Committee for the redefinition of myocardial infarction. J Am Coll Cardiol 2000;36(3):959-969. [PubMed: 10987628]

46. Braunwald E, Antman EM, Beasley JW, et al. ACC/AHA guidelines for the management of patients with unstable angina and non-ST-segment elevation myocardial infarction. A report of the American College of Cardiology/American Heart Association Task Force on Practice Guidelines (Committee on the Management of Patients With Unstable Angina). J Am Coll Cardiol 2000;36(3):970-1062. [PubMed: 10987629] 
47. Antman EM, Tanasijevic MJ, Thompson B, et al. Cardiac-specific troponin I levels to predict the risk of mortality in patients with acute coronary syndromes. N Engl J Med 1996;335(18):1342-1349. [PubMed: 8857017]

48. Ohman EM, Armstrong PW, Christenson RH, et al. Cardiac troponin T levels for risk stratification in acute myocardial ischemia. GUSTO IIA Investigators. N Engl J Med 1996;335(18):1333-1341. [PubMed: 8857016]

49. Norris RM. Dissent from the consensus on the redefinition of myocardial infarction. Eur Heart $\mathrm{J}$ 2001;22(17):1626-1627. [PubMed: 11492994]

50. Birkhead JS, Norris RM. Redefinition of myocardial infarction. Lancet 2001;358(9283):764. [PubMed: 11556352]

51. Jolobe OM. Redefinition of myocardial infarction. Lancet 2001;358(9283):764. [PubMed: 11556354]

52. Richards AM, Lainchbury JG, Nicholls MG. Unsatisfactory redefinition of myocardial infarction. Lancet 2001;357(9269):1635-1636. [PubMed: 11425362]

53. Tunstall-Pedoe H. Redefinition of myocardial infarction by a consensus dissenter. J Am Coll Cardiol 2001;37(5):1472-1474. [PubMed: 11300464]

54. Tunstall-Pedoe H. Comment on the ESC/ACC redefinition of myocardial infarction by a consensus dissenter. Eur Heart J 2001;22(7):613-615. [PubMed: 11259153]

55. Meier MA, Al-Badr WH, Cooper JV, et al. The new definition of myocardial infarction: diagnostic and prognostic implications in patients with acute coronary syndromes. Arch Intern Med Jul 22;2002 162(14):1585-1589. [PubMed: 12123401]

56. Koukkunen H, Penttila K, Kemppainen A, et al. Differences in the diagnosis of myocardial infarction by troponin T compared with clinical and epidemiologic criteria. Am J Cardiol 2001;88(7):727-731. [PubMed: 11589837]

57. Kontos MC, Fritz LM, Anderson FP, Tatum JL, Ornato JP, Jesse RL. Impact of the troponin standard on the prevalence of acute myocardial infarction. Am Heart J Sep 2003;146(3):446-452.

58. Jaffe AS. Elevations of troponin - False positive, the real truth. Cardiovascular Toxicology 2001;1 (2):87-92. [PubMed: 12213978]

59. Apple FS, Wu AH, Jaffe AS. European Society of Cardiology and American College of Cardiology guidelines for redefinition of myocardial infarction: how to use existing assays clinically and for clinical trials. Am Heart J Dec 2002;144(6):981-986.

60. Jaffe AS, Katus H. Acute coronary syndrome biomarkers: the need for more adequate reporting. Circulation 2004;110(2):104-106. [PubMed: 15249513]

61. Jaffe A. Caveat emptor. Am J Med Aug 15;2003 115(3):241-244. [PubMed: 12935832]

62. Apple FS, Quist HE, Doyle PJ, Otto AP, Murakami MM. Plasma 99th percentile reference limits for cardiac troponin and creatine kinase MB mass for use with European Society of Cardiology/American College of Cardiology consensus recommendations. Clin Chem Aug 2003;49(8):1331-1336.

63. Alpert JS, Thygesen K, Antman E, Bassand JP, et al. Myocardial infarction redefined--a consensus document of The Joint European Society of Cardiology/American College of Cardiology Committee for the redefinition of myocardial infarction. J Am Coll Cardiol 2000;36(3):959-969. [PubMed: 10987628]

64. Salomaa V, Ketonen M, Koukkunen H, et al. The effect of correcting for troponins on trends in coronary heart disease events in Finland during 1993-2002: the FINAMI study. Eur Heart J. Jul 3;2006

65. Roger VL, Killian JM, Weston SA, et al. Redefinition of myocardial infarction: prospective evaluation in the community. Circulation Aug 22;2006 114(8):790-797. [PubMed: 16908764]

66. Ng SM, Krishnaswamy P, Morrisey R, Clopton P, Fitzgerald R, Maisel AS. Mitigation of the clinical significance of spurious elevations of cardiac troponin I in settings of coronary ischemia using serial testing of multiple cardiac markers. Am J Cardiol 2001;87(8):994-999. A994. [PubMed: 11305993]

67. Tunstall-Pedoe H, Vanuzzo D, Hobbs M, et al. Estimation of contribution of changes in coronary care to improving survival, event rates, and coronary heart disease mortality across the WHO MONICA Project populations. Lancet Feb 26;2000 355(9205):688-700. [PubMed: 10703800]

68. Laatikainen T, Critchley J, Vartiainen E, Salomaa V, Ketonen M, Capewell S. Explaining the decline in coronary heart disease mortality in Finland between 1982 and 1997. Am J Epidemiol Oct 15;2005 162(8):764-773. [PubMed: 16150890] 
69. Fox KA, Birkhead J, Wilcox R, Knight C, Barth J. British Cardiac Society Working Group on the definition of myocardial infarction. Heart Jun 2004;90(6):603-09.

70. Roger VL, Jacobsen SJ, Weston S, et al. Trends in the Incidence and Survival of Patients with Hospitalized Myocardial Infarction, Olmsted County, Minnesota, 1979 to 1994. Annals of Internal Medicine 2002;136:341-348. [PubMed: 11874305]

71. Goldberg RJ, Konstam MA. Assessing the population burden from heart failure: need for sentinel population-based surveillance systems. Arch Intern Med 1999;159(1):15-17. [PubMed: 9892324] 
Table 1

Incidence of myocardial infarction in selected community studies

\begin{tabular}{|c|c|c|c|c|}
\hline Study & Time period & Incidence Per 100,000 ${ }^{*}$ & $\begin{array}{l}\text { Temporal trends in } \\
\text { incidence }\end{array}$ & Comment \\
\hline ARIC $^{31}$ & 1987-1994 & $\begin{array}{l}\text { Women: } 190 \\
\text { Men: } 410\end{array}$ & Stable or increasing & Ages 35-74 \\
\hline Minnesota Heart Survey ${ }^{33}$ & 1985-1997 & & Decline & Ages 35-74 \\
\hline Olmsted County Study 35,36 & $1979-1998$ & Overall 205 & $\begin{array}{l}\text { Stable overall; age/sex- } \\
\text { specific diverging trends }\end{array}$ & $\begin{array}{l}\text { No upper age } \\
\text { limit }\end{array}$ \\
\hline Worcester Heart Attack Study ${ }^{34}$ & $1975-1995$ & Overall 244 & $\begin{array}{l}\text { Increase in earlier years } \\
\text { followed by decline and } \\
\text { plateau }\end{array}$ & $\begin{array}{l}\text { No upper age } \\
\text { limit }\end{array}$ \\
\hline Corpus Christi Study ${ }^{24}$ & 1988-1992 & $\begin{array}{l}\text { MA Women: } 354 \\
\text { NHW Women: } 224 \\
\text { MA Men: } 486 \\
\text { NHW Men: } 346\end{array}$ & --- & Ages $25-74$ \\
\hline
\end{tabular}

* Rates are age-adjusted and the numbers presented pertain to the first years of each study that include a large time span. MA denotes Mexican American, NHW denotes non-Hispanic White 
Table 2

Case fatality rates of myocardial infarction in selected community surveillance studies

\begin{tabular}{|c|r|r|r|r|}
\hline Studv & Time period & Case fatality rate & Temporal trends & Comment \\
\hline ARIC $^{31}$ & $1987-1994$ & $\begin{array}{c}\text { Men 9\% } \\
\text { Women } 11 \%\end{array}$ & Mortality declined over time & 28 -day mortality \\
\hline Minnesota Heart Survey $^{33}$ & $1985-1997$ & $\begin{array}{c}\text { Men 13\% } \\
\text { Women } 16 \%\end{array}$ & Mortality declined over time & 28 -day mortality \\
\hline Olmsted County Study $^{70}$ & $1979-1994$ & $12 \%$ & $\begin{array}{c}\text { Mortality declined over time only in } \\
\text { vounger persons }\end{array}$ & 28 -day mortality \\
\hline Worcester Heart Attack Study $^{71}$ & $1975-1995$ & $18 \%$ & Mortality declined over time & In-hospital deaths \\
\hline
\end{tabular}

* Numbers are age-adjusted and pertain to the first year of the study period. 